\title{
Cardiovascular risk factors among industrial workers: a cross-sectional study from eastern Nepal
}

\author{
Prajjwal Pyakurel ${ }^{1 *}$, Prahlad Karki ${ }^{2}$, Madhab Lamsal ${ }^{3}$, Anup Ghimire ${ }^{1}$ and Paras Kumar Pokharel ${ }^{1}$
}

\begin{abstract}
Background: Cardiovascular diseases (CVD) are the number one cause of death globally, more people die annually from CVDs than from any other cause. An estimated 17.5 million people died from CVD in 2012, representing 46.2 \% of all NCD death globally. An accurate characteristic of the cardiovascular risk factors in a specified population group is essential for the implementation of educational campaign. However, there are no reliable CVD risk factors burden, nor of its awareness and treatment status in Nepal industrial settings. We aimed to assess cardiovascular risk factors among men age 20-59 years in one of the largest industrial corridor of Eastern Nepal.

Methods: A total of 494 industrial workers between ages of 20-59 years, from two industries participated in the study. Pretested semi-structured questionnaire was used to collect the information. Primary outcome was cardiovascular risk factors based on STEPS survey and study on non-communicable disease in Nepal. A semi-structured questionnaire was used to interview 494 industrial workers. Lipid profile and serum blood glucose of 406 workers and electrocardiogram of 400 workers was done.
\end{abstract}

Results: The prevalence of cardiovascular disease (CVD) was $13.8 \%$. Those who were $>45$ years were 2.72 times more likely to develop CVD. Those who smoked more pack year, had family history of hypertension (HTN) and consumed no fruits were 4.32, 1.90.2.47 times more likely to develop CVD. Low density Lipoprotein (LDL) level $<130$ was found to be protective compared to LDL level above $\geq 130$. On adjusted analysis those who did not consume fruits and had high LDL level were 3.32 and 3.03 more likely to develop CVD.

Conclusion: There is high prevalence of CVD risk factors. Although majority of them are literate there is lack of health education and awareness among young male population in an eastern Nepal industrial setting.

Keywords: Cardiovascular disease, Occupational health, Industrial workers

\section{Background}

CVD are the number one cause of death globally, more people die annually from CVD than from any other cause. An estimated 17.5 million people died from CVD in 2012, representing $46.2 \%$ of all Non-communicable disease (NCD) death [1]. Of these deaths, an estimated 7.4 million were due to heart attack and 6.7 million were due to stroke [1]. Low middle income country (LMIC) are disproportionally affected by CVD, over $80 \%$ of CVD deaths takes place in LMIC. In 2012 heart disease and stroke

\footnotetext{
*Correspondence: prazzwal@gmail.com

${ }^{1}$ School of Public Health and Community Medicine, B.P.Koirala Institute of Health Sciences, Postal Address: 56705, Dharan, Nepal

Full list of author information is available at the end of the article
}

were among the top three causes of years of life lost due to premature mortality [1]. The number of people, dying from CVDs, mainly heart disease and stroke, will increase to reach 23.3 million by $2030[2,3]$.

Over the last four decades, the rate of death from CVD has declined in high- income countries, owing to reduction in CVD risk factors and better management. Recent studies indicate that, although the risk-factor burden is lower in low-income countries, the rates of major CVD and death are substantially higher than high-income countries [1]. CVD mortality rates in the South Asian countries are much higher than the East Asian countries [4]. Estimates from the Global Burden of Disease (GBD) study suggest that by the year 2020, India alone will have 
more individuals with CVD than in any other region [5]. Unfortunately, no large-scale, methodologically sound, epidemiological studies are available in these populations to estimate the true incidence of cardiovascular events.

In Nepal, $42 \%$ of deaths are caused by NCD and nearly $35 \%$ of deaths are caused by CVD, cancer, chronic obstructive pulmonary disease and diabetes mellitus [6]. Prevalence of coronary heart diseases in eastern region was $5.7 \%$ in 2005. Similarly, prevalence of hypertension was 22.7 \% in Dharan municipality [7]. Studies have shown that the prevalence of hypertension in adult population was around $20 \%$ in urban population [8]. According to the data of 'Sunsari Health Survey' of the year 1993, the prevalence of diabetes and hypertension in Sunsari Districtfrom eastern Nepal, was about $6 \%$ and $5.1 \%$ respectively in adults [9]. The NCD risk factors: STEPS survey Nepal 2013 showed prevalence of smoking-18.5\%, alcohol-17.4\%, HTN-23.4 \%, diabetes-3 \%, hypercholesterolemia-22.7 \% and hypertriglyceridaemia-25.2 \% [10].

The concept of occupational safety and health (OSH) in Nepal is in initial stage. The government of Nepal has enforced concepts of OSH through its Labor Act 1992; it has highlighted few issues and provisions on working hours, physical infrastructural setup, yearly medical examination and provisions of safety measures in work etc. It has already endorsed 9 conventions passed by International Labor Organization (ILO) but has not yet ratified convention No. 155 which solely bears OSH obligations [11].

An accurate characteristic of the CVDs risk factors in a specified population is essential for the implementation of educational campaigns [12]. Identifying risk factors and implementing certain intervention will definitely help to reduce CVD risk. However, there are no reliable study on burden of risk factors, awareness and treatment of CVD in industrial setting of Nepal. We aimed to assess CVDs risk factors among men age 20-59 years in one of the largest industrial corridor of Eastern Nepal.

\section{Methods}

A cross sectional study was conducted among men age 20-59 years in one medium and one large size industries in the industrial Corridor of Eastern Nepal from July 2012 to July 2013. Medium size industries was defined as industries with fixed assets between Nepalese rupees (NRs) 30 million and 100 million whereas large size industries was defined as investment of more than NRs 100 million in fixed assets. Female workers and all the small industries workers were excluded from the study.

The intention was not to select particular type of industry (e.g. metal, beverages etc.) but to select an isolated population whose CVD burden are still hidden and where preventive programmes can be initiated. Industrial setting, with their intramural resources and healthcare infrastructure, are ideal for initiating preventive activities to increase the awareness and control of CVD. Two industries were selected by simple random sampling through lottery method from the industrial cue sheet of Large and Medium size industries, provided by Morang Merchant Association Biratnagar Nepal, an organization working for the welfare of industries in Eastern Nepal. During lottery method each industry name was transferred from a que-sheet and was put on a piece of paper. The piece of paper were placed in a container and thoroughly mixed. The required number of industries was selected without looking the name of the industries. Industries selected were Hulas Wire Industries Private Pvt. Limited which was the large size industry and Pragati Textile Industries Pvt. Limited which was the medium size industries. Workers were selected through systematic random sampling. List of workers working for various duration of years and various shifts excluding the night shifts were made. Altogether there were 1000 workers from these two industries after exclusion of night workers. Dividing the total population by the required sample size estimated sampling interval of 2.02 was made. Taking round figure of 2 workers, every third workers were selected as the sample. Workers who were unable to provide consent were excluded. If the total sample size was not met due to workers not providing consent, list of workers who were not considered in the initial stage was made and sample was drawn by similar process through systematic random sampling.

According to the study done by Kaur et al. [13] in India the least prevalence risk factor of CVD was diabetes which was $16.3 \%$.

Prevalence $(\mathrm{p})=16.3 \%$

Compliment of prevalence $(\mathrm{q})=100-16.3=83.7 \%$

Permissible Error $(\mathrm{PE})$ at $20 \%, \mathrm{~L}=20 \%$ of $16.3=3.26$

Sample size $(\mathrm{n})=(\mathrm{Z} 1-\alpha) 2 \times \mathrm{pq} / \mathrm{L} 2$

$=(1.96) 2 \times 16.3 \times 83.7 /(3.26) 2$

$=493.30(494)$

The study site was the Sunsari-Morang Industrial Corridor of Eastern Nepal which is the $28 \mathrm{~km}$ long corridor extending from Khanar of Sunsari District to Rani of Morang district of eastern Nepal, where majority of medium and large sized industries are located.

The data was collected using a pre-tested semi-structured questionnaire. Questions were adopted from WHO STEPS [14] questionnaire and a hospital based study on noncommunicable disease in Nepal [15]. Risk factors were based on self-report, physical and bio-chemical measurement. The questionnaire was used to elicit information from each study participant for socio-demographic characteristics, lifestyle-related factors and physical and bio-chemical measurements.

Cardiovascular positive cases was defined as those cases which had been diagnosed on the basis of documentation, evidence of treatment of CVD, positive rose angina questionnaire and with presence of Electrocardiogram (ECG) 
abnormalities 1-1-1, 1-1-2, 1-1-3, 1-1-4, 1-1-5, 1-1-6 and 11-7 representing major $Q$ wave 4-1-1 and 4-1-2 representing ST-T changes and 5-1 and 5-2 representing $\mathrm{T}$ waves changes in the Minnesota coding [16].

Two blood pressure measurements were taken using standard techniques. The measurements were obtained half an hour apart. The lower of the two measurements was used for analysis. Height was measured in meters. Weight was measured in kilogram [17]. Waists circumference (WC) was measured at the centre point of the subcostal margin in the mid-axillary line and the highest point of the iliac crest in the mid-axillary line. Hip circumferences $(\mathrm{HC})$ were measured at the level of the greater trochanter. ECGs were read by cardiologist and coded using the Minnesota coding system [16].

Blood samples were drawn by trained personnel, centrifuged and stored for analysis. Laboratory measurements included estimation of fasting blood glucose, total cholesterol, triglycerides, high density lipoprotein (HDL) and LDL. Glucose was analyzed by oxidase method (GOD-POD), cholesterol by (CHOD-PAP) method, TG by (GPO-PAP) method, HDL by Cholesterol Liquicolor test kit and LDL by Friedewald formula [18-22].

\section{Analysis}

All data was entered in Microsoft XP Excel spread sheet and converted into SPSS (Statistical Package for Social Sciences) Version 17 program for statistical analysis. The significance of proportion was used by examining Chi-square test and Fisher Exact test. The probability of significance was set at $5 \%$ level of significance and 95\%confidence interval. Odd's ratio was calculated.

\section{Ethical clearance}

This study was conducted after obtaining ethical clearance from Institutional Ethical Review Board of B. P. Koirala Institute of Health Sciences, Dharan, Nepal. Approval for conducting the study was obtained both from the management and the employee representative. Written informed consent from the study subject was taken after explaining all the procedure in Nepali.

\section{Results}

A face to face semi-structured interview was done among 494 industrial workers over a course of one year. Response rate for face to face interview was $100 \%$. Lipid profile and serum blood glucose of 406 workers and ECG of 400 workers were done.17.81\% of workers for blood test examination and $19.02 \%$ of workers for ECG examination didn't participated.

\section{Demographic characteristics}

The mean age of the participant was $33.56 \pm 8.75$ years with $40.7 \%$ of the workers in age group of $20-29$ years.
Majority of them $(97.6 \%)$ were literate with more than half $(60.6 \%)$ completed some secondary education. About 2/3rd (74.5\%) were below the poverty line.

Behavioural CVD risk factor profile showed $63.2 \%$ did vigorous intensity exercise. Most of them (90.5\%) were non-vegetarian. More than 1/3rd (38.3\%) did not consume fruits/week. Majority of them (97.4\%) consumed salt more than that recommended by World Health Organization (WHO) of $35 \mathrm{~g} /$ week. About $40.2 \%$ were current smoker. Local Rakhsi (Home-made alcohol) was consumed by about $63.9 \%$ of the workers. Almost $30 \%$ of the workers were hazardous drinkers (Table 1).

Physical and biochemical parameter showed mean pulse rate of $75.04 \pm 8.85$ beats $/ \mathrm{min}$. About $41 \%$ were prehypertensive. Body mass index (BMI) was at increased risk and at higher high risk for $46 \%$ of the participants as per the BMI for Asian classification. Almost half of them $(46.9 \%)$ had central obesity. Hyperglycaemia was seen in $4.2 \%$ and dyslipidemia in $84.5 \%$ of the workers (Table 2).

Table 1 Behavioural risk factor profile of workers $(n=494)$

\begin{tabular}{|c|c|}
\hline Characteristics & Percentage \\
\hline \multicolumn{2}{|l|}{ Physical activity } \\
\hline Vigorous intensity exercise & 63.2 \\
\hline Moderate intensity exercise & 36.8 \\
\hline \multicolumn{2}{|l|}{ Dietary Habit } \\
\hline Vegetarian & 9.5 \\
\hline Non-vegetarian & 90.5 \\
\hline \multicolumn{2}{|l|}{ Fruit Consumption/week } \\
\hline None Serving & 38.3 \\
\hline 1 Serving & 25.1 \\
\hline$>1$ Serving & 36.6 \\
\hline \multicolumn{2}{|l|}{ Salt individual/week } \\
\hline$\leq 35 \mathrm{~g}$ & 2.6 \\
\hline$>35 \mathrm{~g}$ & 97.4 \\
\hline \multicolumn{2}{|l|}{ Smoke Product User $(n=251)$} \\
\hline Current & 40.4 \\
\hline Former & 10.5 \\
\hline Never & 49.1 \\
\hline \multicolumn{2}{|l|}{ Pack Year $(n=251)$} \\
\hline$\leq 5$ & 94.4 \\
\hline$>5$ & 5.6 \\
\hline \multicolumn{2}{|l|}{ Alcohol type among user $(n=366)$} \\
\hline Local Rakshi & 63.9 \\
\hline Beer & 16.7 \\
\hline Whisky, Rum, Gin & 19.4 \\
\hline \multicolumn{2}{|l|}{ Alcohol amount/week $(n=366)$} \\
\hline$<21$ units & 69.4 \\
\hline$\geq 21$ units & 30.6 \\
\hline
\end{tabular}


Table 2 Physical and Biochemical profile of workers

\begin{tabular}{|c|c|}
\hline Characteristics & Percentage \\
\hline \multicolumn{2}{|l|}{ JNC-7 classification of HTN $(n=494)$} \\
\hline Normal & 25 \\
\hline Pre-hypertension & 41.4 \\
\hline Hypertension stage 1 & 24.5 \\
\hline Hypertension stage 2 & 9.1 \\
\hline \multicolumn{2}{|l|}{ BMI For Asian Population $(n=494)$} \\
\hline Underweight $\left(<18.5 \mathrm{~kg} / \mathrm{m}^{2}\right)$ & 6.3 \\
\hline Increased but acceptable risk (18.5- $\left.23 \mathrm{~kg} / \mathrm{m}^{2}\right)$ & 46.8 \\
\hline Increased risk $\left(23-27.5 \mathrm{~kg} / \mathrm{m}^{2}\right)$ & 35.8 \\
\hline Higher High Risk $(\geq 27.5$ kg/m²) & 11.1 \\
\hline \multicolumn{2}{|l|}{ Waist- Hip Ratio $(n=494)$} \\
\hline Normal $(<0.90)$ & 53 \\
\hline Central obesity $(>0.90)$ & 47 \\
\hline \multicolumn{2}{|l|}{ Serum Biochemistry Profile $(n=406)$} \\
\hline Diabetes $(\geq 126$ mg/dl) & 4.2 \\
\hline $\begin{array}{l}\text { Impaired fasting blood glucose }(\geq 110 \mathrm{mg} / \mathrm{dl} \\
\text { and }<126 \mathrm{mg} / \mathrm{dl})\end{array}$ & 30.5 \\
\hline Hypercholesterolemia & 44.1 \\
\hline Hypertriglyceridemia & 49.3 \\
\hline Decreased HDL & 65.8 \\
\hline Dyslipidaemia & 84.5 \\
\hline Cardiovascular disease & 13.8 \\
\hline
\end{tabular}

Those who were $>45$ years were 2.72 times more likely to had CVD compared to those $\leq 45$ years. $(\mathrm{OR}=2.72$, CI 1.35 to 5.40) Similarly, those who did not consume fruits were 2.47 times more likely to develop CVD. $(\mathrm{OR}=2.47$, 1.47-4.16) More pack year of smoking was related to more chances of developing CVD. Those who consumed more than 5 pack years were 4.32 times more likely to develop CVD compared to those who smoked $\leq 5$ pack years. $(\mathrm{OR}=4.32$, 1.34-13.84). Those who had family history of HTN were 1.90 times more likely to develop CVD compared to those who did not had family history of HTN. (OR =1.90, CI 1.14-3.19). Similarly those who had a LDL level of $<130$ were 0.55 times more likely to be protective from CVD compared to those who had LDL level of $\geq 130$. (OR $=0.31-0.99)$ (Table 3$)$.

Binary logistic regression analysis revealed that those who did not consumed fruit once a week had 3 times more chances of developing CVD compared to those who did consumed fruits (adjusted OR (AOR) 3.58, CI 1.24-8.87), as shown in Table 4. Similary those who had high LDL of $<130$ were 0.18 times more likely to be protective from CVD compared to those who had LDL level of $\geq 130$ (adjuster OR $(A O R)=0.35-0.97$ ). Potential confounders were identified through literature search and those variables whose $\mathrm{P}$ value was $<0.05$ were entered in the logistic regression model. The following variables were adjusted in the regression model (age, HTN, pack year of smoking, tobacco chewing user, diabetes, physical activity, total cholesterol, triglycerides, HDL, LDL, dietary history, fruit consumption/week, waist-hip ratio, earplug used and working hours/week) (Table 4).

\section{Discussion}

This study done in industrial setting among relatively young urban population, found prevalence of cardiovascular risk factors to be high. The study had included industrial workers of age 20-59 years which were similar to study done among industrial workers in one of the large industry in northern India [16]. The mean age of the participants were 33.56 years which were lower than a similar study done among Brazilian industry workers [12]. Bulletin on CVD risk test showed men age 45 years or older were at greater risk of CVD [23].

More than half of the workers had completed some secondary education in our study which were comparatively less than study done by Prabhakharan et al. in Northern India where $66.4 \%$ were graduate/postgraduate/professional [16].

Workers were involved in moderate and vigorous physical activity at any time during work, leisure time and household activities. Although workers showed high physical activity at work presence of risk factors still seemed to be high. In a study done by Mehan et al. in industrial setting none of the subjects, including workers, were found to be engaged in heavy activities at workplace. Majority of subjects were engaged in light activities and moderate activities. This could be due to the differences in characteristics of industrial setting [24].

Non-vegetarian comprised about $90 \%$ of our study population. A study among chemical industrial workers in India showed most of the respondents was vegetarian in contrast to our study. Although there were changes in dietary pattern in both industries, CVD risk factors still seemed to be high. This showed the role of multiple risk factors in the causation of disease. Most of the respondent in our study consumed less fruits. In a similar study done by Mehan et al. the mean daily fruits and vegetables consumption were less than the recommended WHO guideline which were similar to our study [24]. In our study those who consumed no fruits were more likely to develop CVD in comparison to those who consumed fruits. (OR $=2.47$, CI 1.47 to 4.16 ). Similarly careful analysis of INTERHEART data revealed, South-Asians had lower prevalence of vegetables and food intake compared to rest of the world [25].

Respondents consumed more than $35 \mathrm{~g}$ of salt/week. Most of them consumed salt and pickle for taste as their regular diet. WHO guideline recommends taking too much salt whether in the form of added salt in meal or 
Table 3 Risk factors associated with Cardiovascular Disease (Bivariate analysis)

\begin{tabular}{|c|c|c|c|c|c|}
\hline \multirow[t]{2}{*}{ Variable } & \multicolumn{3}{|c|}{ Cardiovascular disease } & \multirow[t]{2}{*}{ Odd's Ratio } & \multirow[t]{2}{*}{ Confidence Interval } \\
\hline & Positive & Negative & Total & & \\
\hline \multicolumn{6}{|l|}{ Age } \\
\hline$>45$ & $13(27.7)$ & $34(72.3)$ & $47(100)$ & \multirow[t]{2}{*}{2.72} & \multirow[t]{2}{*}{$1.35-5.40$} \\
\hline$\leq 45$ & $55(12.3)$ & $392(87.7)$ & $447(100)$ & & \\
\hline \multicolumn{6}{|l|}{ Fruits/week } \\
\hline No fruit consumption & 39 (20.6) & $150(79.4)$ & $189(100)$ & \multirow[t]{2}{*}{2.47} & \multirow[t]{2}{*}{$1.47-4.16$} \\
\hline Fruit consumption & $29(9.5)$ & $276(90.5)$ & $305(100)$ & & \\
\hline \multicolumn{6}{|l|}{ Pack year of smoking } \\
\hline$>5$ pack year & $5(35.7)$ & $9(64.3)$ & $14(100)$ & \multirow[t]{2}{*}{4.32} & \multirow[t]{2}{*}{$1.34-13.84$} \\
\hline$\leq 5$ pack year & $27(11.4)$ & $210(88.6)$ & $237(100)$ & & \\
\hline \multicolumn{6}{|c|}{ Family History of Hypertension } \\
\hline Yes & 36 (18.6) & $158(81.4)$ & $194(100)$ & \multirow[t]{2}{*}{1.90} & \multirow[t]{2}{*}{$1.14-3.19$} \\
\hline NO & $32(10.7)$ & $268(89.3)$ & $300(100)$ & & \\
\hline \multicolumn{6}{|l|}{ LDL Cholesterol } \\
\hline$<130$ & $22(10.7)$ & $183(89.3)$ & $205(100)$ & \multirow[t]{2}{*}{0.55} & \multirow[t]{2}{*}{$0.31-0.99$} \\
\hline$\geq 130$ & $34(17.7)$ & $158(82.3)$ & $192(100)$ & & \\
\hline
\end{tabular}

taking regular salt containing foodstuffs increases blood pressure and subsequent chances of developing CVD [26].

Current smokers comprised of more than $1 / 3 \mathrm{rd}$ of the respondents. In study done by Shields et al. comparing those who had never smoked daily, current daily smokers had $60 \%$ higher risk of incident heart disease during the follow-up period. The relative risk ratio was 1.6 times more in current daily smokers in compared to those who had never smoked [27]. In our study those who consumed $>5$ pack years of cigarettes were more likely to develop CVD compared to those who consumed $\leq 5$ pack years of cigarettes $(\mathrm{OR}=4.32$, CI 1.34 to 13.84). In Framingham risk prediction equations for incidence of CVDs using detailed measures for smoking, compared to never smokers the risk of CVD incidence increased with pack-years [28].

About $30 \%$ of the workers drank more than the recommended 21 units/week and were hazardous drinkers, $33.6 \%$ were hypertensive, $11.1 \%$ were considered high to very high risk as per the BMI for Asian Population, $46.96 \%$ had central obesity, $4.2 \%$ had hyperglycaemia and about $85 \%$ had dyslipidemia.

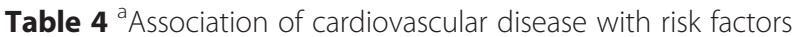
(Multivariate analysis)

\begin{tabular}{rccc}
\hline Significant variable & Significant values & Adjusted OR & $95 \% \mathrm{Cl}$ \\
\hline No fruit consumption & 0.02 & 3.58 & $1.24-8.87$ \\
LDL Cholesterol & 0.04 & 0.18 & $0.35-0.97$ \\
\hline
\end{tabular}

${ }^{a}$ Age, HTN, pack year of smoking, tobacco chewing user, diabetes, physical activity, total cholesterol, triglycerides, $\mathrm{HDL}, \mathrm{LDL}$, dietary history, fruit consumption/week, waist-hip ratio, earplug used and working hours/week
Study done by Roy et al. on impact of alcohol on CHD in 10 medium-to large size industries from diverse sites found possible harm of alcohol for CHD risk in Indian men. However this relationship needs to be further examined in large, prospective study [29]. Study done by Sharma et al. on general population of Nepal showed prevalence of HTN to be $34 \%$ which is comparable to our study [30]. Similarly other studies done in India showed $12.2 \%$ were in the high to very high risk as per the BMI which is comparable to our study.(15) A review done by Vaidya et al. on obesity prevalence in Nepal showed high levels of central obesity (between $40 \%$ and $60 \%)$ across different demographic groups, which could be comparable to our study [7].

Dyslipidemia were seen among $85 \%$ of the respondents. Most of the industrial population resides in and around Duhabi and Khanar of Sunsari district in Koshi zone of south-eastern Nepal which is rapidly urbanizing. With growing population, changes in lifestyle and food-habit especially in suburban and rural areas of the country, there is a potential threat of increasing risk factor for CVDs especially Coronary Heart Disease (CHD). The healthy traditional plant-based diets are being replaced by cheaper calorie dense high-fat foods. There is high intake of saturated and trans-saturated fatty acid. All factors have led to the occurrence of dyslipidemia especially hypercholesterolemia [30, 31].

\section{Strength of the study}

This is one of first attempts to understand CVD risk factors among industrial population in Nepal. We tried to explore occupational sector which is neglected area of 
research in Nepal. In study methodology we have used pre-tested questionnaire, scientific calculation of sample size, random and systematic sampling and calculation of unadjusted and adjusted Odd's ratio which adds to the strength of our study.

\section{Limitation}

The study was carried out in industrial setting and only in males hence it could not be representative of general population. The results could not be generalized to individuals older than 60 years, in whom the risk factors as well as disease burden is higher than this population. Night shift workers were excluded in the study. This is the first kind of study done in industrial sector of Nepal hence comparison could not be made with other industries of the country.

\section{Conclusion}

There is high prevalence of CVD risk factors among industrial workers. Although the study population was not representative of general industrial population we believe that it does represent the similar kind of CVD risk factors burden among many of medium and large size industries in Eastern Nepal. Though this seems to be a small occupational health survey but it adds on the risk factors prevalent in the industrial set-up and thus focuses the attention of cardiovascular epidemiologist and researcher to conduct more studies.

\begin{abstract}
Abbreviation
BMI: body mass index; CHD: coronary heart disease; CHOD -PAP: enzymatic colorimetric determination of serum cholesterol; CVD: cardiovascular disease; ECG: electrocardiogram; GBD: global burden of disease; GOD-POD: glucose oxidase method; GPO-PA method: quantitative estimation of triglycerides in serum or plasma; HC: height circumference; HDL: high density lipoprotein; HTN: hypertension; ILO: international labour organization; LDL: low density Lipoprotein; LMIC: low-middle income country; NCD: non-communicable disease; NRs: nepalese rupees; OSH: occupational safety and health; Pvt.: private; SPSS: statistical package for social science; WC: waist circumference.
\end{abstract}

\section{Competing interests}

The authors declare that they have no competing interests.

\section{Authors' contributions}

PP, PKP and ML made substantial contributions to the conception or design of the work or the acquisition, analysis, and interpretation of data for the work. PP, PK and ML and AG revised the work critically for important intellectual content. PP, PKP, PK and AG gave final approval of the version to be published. PP, PK, PKP, AG \& ML all agree to be accountable for all aspects of the work in ensuring that questions related to the accuracy or integrity of any part of the work are appropriately investigated and resolved. All authors read and approved the final manuscript.

\section{Acknowledgement}

A very special acknowledgement goes to Dr. Sanjiv Kumar Sharma (Prof, Internal medicine) who have always encouraged and supported me during difficult times and without his help this work would have been very difficult to accomplish. Sincere thanks goes to Kidney, Hypertension, Diabetes, Cardiovascular Disease (KHDC) team members Dr. SadikshyaAdhikhariSapkota, Kaji Man Giri and MamitRai. I also consider it very important to offer thankfulness to Dr. VivekKattel (Assistant Professor, Internal medicine), Prakash Chandra Karkee, Anil Khadka, Ram Binay Shah, Bsc MLT (2011batch), Anup, Aastha (interns), Kissan, Safal, Rajendra, Prakash, Jasraj (MBBS final year students) for their cooperation. I also like to thank Dr. Puspanjali Adhikari for grammer and language correction. My earnest appreciation goes to SanjeevJha, Shree Narayan Majhi (Hulas Wire Industries Pvt. Ltd.), PradeepNiraula, BhadduSardar (Pragati textile Ltd.) and to all those factory workers who agreed to be a part of this study. My appreciation also goes to B.P. Koirala Institute of Health Sciences for providing me opportunity of carrying out research in this topic. Lastly I would like to thank all the people who directly or indirectly supported my work.

\section{Author details}

${ }^{1}$ School of Public Health and Community Medicine, B.P.Koirala Institute of Health Sciences, Postal Address: 56705, Dharan, Nepal. 'Department of Internal Medicine, B.P.Koiralalnstitue of Health Sciences, Dharan, Nepal. ${ }^{3}$ Department of Bio-chemistry, B.P.Koiralalnstitue of Health Sciences, Dharan, Nepal.

Received: 11 June 2015 Accepted: 17 April 2016

Published online: 14 May 2016

\section{References}

1. World Health Organization. Global status report on non-communicable disease 2014. ISBN 9789241564854 Switzerland: WHO Press, World Health Organization; 2014 http://www.who.int/nmh/publications/ncd-status-report2014/en/(accessed 19 Dec 2015)

2. World Health organization. Global status report on non-communicable diseases 2010. ISBN 9789240686458 Switzerland: WHO Press, World Health Organization; 2010 http://www.who.int/nmh/publications/ncd_ report_full_en.pdf (accessed 17 Dec 2015)

3. Mathers CD, Loncar D. Projections of global mortality and burden of disease from 2002 to 2030. PLoSMed. 2006:3(11):e442. http://journals.plos.org/plosmedicine/ article?id=10.1371/journal.pmed.0030442 (accessed date 19 Dec 2015).

4. Ueshima H, Sekikawa A, Miura K, Turin TC, Takashima N, Kita Y, et al. Cardiovascular disease and risk factors in Asia: a selected review. Circulation. 2008;118(25):2702-9. http://circ.ahajournals.org/content/118/25/2702.full.pdf (accessed date 19 Dec 2015).

5. Christopher J, Murray L, Lopez A. The global burden of disease. United Kingdom: Harvard University Press; 1996. http:/apps.who.int/iris/bitstream/10665/41864/1/ 0965546608_eng.pdf (access date 19 Dec 2015). ISBN 0-9655466-0-8.

6. Government of Nepal Ministry of Health and Population, Nepal Health Research Council, World Health Organization, Country office for Nepal. Non-Communicable diseses risk factors: STEPS Survey Nepal 2013: Ramsapath Kathmandu, Nepal; National Health Research Council;2013 http://www.searo. who.int/nepal/mediacentre/non_communicable_diseases_risk_factors_steps_ survey_nepal_2013.pdf (accessed date 19 Dec 2015)

7. Vaidya A, Pokharel PK, Nagesh S, Karki P, Kumar S, Majhi S. Prevalence of coronary heart disease in the urban adult males of eastern Nepal: a population-based analytical cross-sectional study. Indian Heart J. 2009;61(4): 341-7. http://indianheartjournal.com/ihj09/july_aug_09/341-347.html (19th Decmber 2015)

8. Maskey A, Sayami A, Pandey R. Coronary artery disease: an emerging epidemic in NEPAL. Journal of Nepal Medical Association. 2003;42:122-4. http://jnma.com.np/files/archive/2003/vol.42, \%20no.146(2003)/Coronary \% 20 Artery \% 20 Disease. pdf (access date 19 Dec 2015).

9. Bhandari GP, Angdembe MR, Dhimal M, Neupane S, Bhusal C. State of non-communicable disease in Nepal. BMC Public Health. 2014;14(23). http://bmcpublichealth.biomedcentral.com/articles/10.1186/1471-2458-1423(18th December 2015).

10. Government of Nepal Ministry of Health and Population, Nepal Health Research Council, World Health Organization, Country office for Nepal. Non-Communicable diseses risk factors: STEPS Survey Nepal 2013: Ramsapath Kathmandu, Nepal; National Health Research Council;2013. http://www.searo.who.int/nepal/ mediacentre/non_communicable_diseases_risk_factors_steps_survey_nepal_ 2013.pdf (accessed date 19 Dec 2015)

11. Joshi SK. Occupational Safety and Health in Nepal. International Journal of Occupational Safety and Health. 2011;1:1-2. http://nepjol.info/index.php/ IJOSH/article/view/5224/4347 (accessed date 20 Dec 2015).

12. Cassani RSL, Nobre F, Filho AP, Schmidt A. Prevalence of cardiovascular risk factors in a population of Brazilian industry workers. Arq Bras Cardiol. 2009; 92(1):16-22. http://www.scielo.br/pdf/abc/v92n1/en_04.pdf (accessed 20 Dec 2015). 
13. Kaur P, Rao TV, Sankarasubbaiyan S, Narayanan AM, Ezhil R, Rao SR, et al. Prevalence and distribution of cardiovascular risk factors in an urban industrial population in south India: a cross-sectional study. J Assoc Physicians India. 2007;55:771-6. http://www.japi.org/november2007/0-771. pdf (access date 20 Dec 2015).

14. World Health Organization. The WHO STEP wise approach to chronic disease risk factor surveillance (STEPS).Geneva, Switzerland: WHO Press. http://www.who.int/chp/steps/STEPS_Instrument_v2.1.pdf (access date 20 Dec 2015)

15. Nepal Health Research Council. Prevalence of non-communicable disease in Nepal,Hospital based study2010. Nepal: S.S Printing Press; 2012. http://www. ncf.org.np/upload/files/611_en_Non_Communicable_diseases.pdf (access date 20 Dec 2015)

16. Prabhakaran D, Shah P, Chaturvedi V, Ramakrishnan L, Manhapra A, Reddy KS. Cardiovascular risk factor prevalence among men in a large industry of northern India. Natl Med J India. 2005;18(2):59-65. http://www.nmji.in/ archives/Nolume_18-2_March_April2005/Original_articles/59-75_1.pdf (accessed date 20 Dec 2015).

17. Glynn M, Drake W. Hutchison's Clinical Methods:An integrated approach to clinical practice. United Kingdom: Saunders Elsevier; 2007.

18. KEE GAD Biogen Pvt. Ltd. Ver. KGGLU104.1/1GLUCOSE (GOD- POD Method, End Point). New Delhi-110028, India. 2010.

19. N.S. BIOTEC MEDICAL EQUIPMENTS. CHOL-MC-0530. CHOLESTEROL (CHOD-PAP) Enzymatic Colorimetric Determination of Serum Cholesterol. Alexandaria-Egypt

20. MEDICHEM MIDDLE EAST Clinical Chemistry Reagents. Cat. No.15181. Triglycerides GPO/PAP Enzymatic colorimetric method. Syria;2010.

21. HUMAN.SU-HDLDD INF 1008401 GB 09-2002-11. HDL CHOLESTEROL liquicolor HDL.Direct Homogenous Test for the Determination of HDLcholesterol Enzymatic Colorimetric test; 2002.

22. General Practice Notebook. Friedwald equation. https:/www.easycalculation. $\mathrm{com} /$ medical/ldl-cholesterol.php (accessed date 20 Dec 2015)

23. Aetna. Cardiovascular Disease Risk Tests. www.aetna.com/cpb/medical/data/ 300_399/0381.html (accessed 20 Dec 2015)

24. Mehan MB, Srivastava N, Pandya H. Profile of non communicable disease risk factors in an industrial setting. J Postgrad Med. 2006;52(3):167-73. http://www.bioline.org.br/pdf?jp06056 (accessed date 20 Dec 2015).

25. Goyal A, Yusuf S. The burden of cardiovascular disease in the Indian subcontinent. Indian J Med Res. 2006;124(3):235-44. http://www.ncbi.nlm. nih.gov/pubmed/17085827 (access date 20th Dec 2015).

26. World Health Organization. Guideline: Sodium intake for adults and children. ISBN 978924150483 6: Geneva, Switzerland; 2012. http://apps. who.int/iris/bitstream/10665/77985/1/9789241504836_eng.pdf?ua=1\&ua=1 (accessed date 20 Dec 2015)

27. Shields M, Wilkins K. Smoking, smoking cessation and heart disease risk: A 16-year follow-up study. Health Reports. 2013;24(2):12-22. http://www. statcan.gc.ca/pub/82-003-x/2013002/article/11770-eng.htm (access date 20 Dec 2015)

28. Mannan H, Stevenson C, Peeters A, Walls H, McNeil J. Framingham risk prediction equations for incidence of cardiovascular disease using detailed measures for smoking. Heart Int. 2010;5(2):e11. http://www.ncbi.nlm.nih.gov/ pmc/articles/PMC3184690/ (accessed date 20 Dec 2015).

29. Roy A, Prabhakaran D, Jeemon P, Thankappan KR, Mohan V, Ramkrishna L et al. Impact of alcohol on coronary heart disease in Indian men. Atherosclerosis 210 (2):531-5. http://www.ncbi.nlm.nih.gov/pubmed/ 20226461 (access date 20 Dec 2015)

30. Sharma SK, Ghimire A, Radhakrishnan J, Thapa L, Shrestha NR, Paudel N, et al. Prevalence of hypertension, obesity, diabetes, and metabolic syndrome in Nepal. Int J Hypertens. 2011;2011:821971. http://www.hindawi. com/journals/ijhy/2011/821971/ (accessed date 20 Dec 2015)

31. Limbu YR, Rai SK, Ono K, Kurokawa M, Yanagida Jl, Rai G, et al. Lipid profile of adult Nepalese population. NepalMedCollJ. 2008;10(1):4-7. http://nmcth. edu/images/gallery/Editorial/NoZ2lyrlimbu.pdf (accesses date 20 Dec 2015)).

\section{Submit your next manuscript to BioMed Central and we will help you at every step:}

- We accept pre-submission inquiries

- Our selector tool helps you to find the most relevant journal

- We provide round the clock customer support

- Convenient online submission

- Thorough peer review

- Inclusion in PubMed and all major indexing services

- Maximum visibility for your research

Submit your manuscript at www.biomedcentral.com/submit
Biomed Central 